\title{
BILATERAL NON-ROTATION OF KIDNEY WITH VASCULAR ANOMALIES- A CASE REPORT
}

\author{
Sheenu Malik Suri'1, Vandana Jain², S. Shrivastava ${ }^{3}$, Arvind Jain ${ }^{4}$
}

HOW TO CITE THIS ARTICLE:

Sheenu Malik Suri, Vandana Jain, S Shrivastava, Arvind Jain. "Bilateral non-rotation of kidney with vascular anomalies- a case report". Journal of Evolution of Medical and Dental Sciences 2013; Vol2, Issue 36, September 9; Page: 6876-6879.

ABSTRACT: During development, the kidney ascends from its original pelvic position to its definitive lumbar position at the end of $5^{\text {th }}$ to $8^{\text {th }}$ week of intrauterine life. It also undergoes rotation, so that the hilum which was initially facing its ventral aspect comes to lie on its medial aspect. However in many instances, the rotation is abnormal or incomplete. Variations in kidney position are very important clinically, for both the complications they may generate and the technical difficulties of certain surgical interventions. Variations in the renal vessels and knowledge of the possibility of these are becoming more important nowadays due to gradual increase in interventional radiological procedures, urological and vascular operations, and renal transplantation. Here we report a case of bilateral non-rotation of kidneys found in a 60 yrs old male cadaver during routine dissection along with unilateral additional renal artery originating from the abdominal aorta. These anomalies were associated with extrarenal calices and pelves.

KEY WORDS: Bilateral Nonrotation, supernumerary arteries, extra renal calyces

INTRODUCTION:- During development, the kidney ascends from its original pelvic position to its definitive lumbar position at the end of the 5th -8th week of intrauterine life. It also undergoes rotation so that the hilum, which was initially facing its ventral aspect, comes to lie on its medial aspect. However, in many instances, the rotation is incomplete or abnormal. Also in standard anatomy textbooks, at the hilum, usually the renal vein is the anterior most with the renal artery posterior to it and the pelvis of kidney lying further posteriorly. Numerous anatomic variations regarding the vascularization of kidneys including presence of multiple arteries with or without congenitally abnormal kidneys have been reported in the literature. Anomalies of renal arteries are more common than are anomalous renal veins. (Gillaspie and Co-workers).

CASE REPORT: Observations made during the dissection of a 60-year old male embedded cadaver was that the left kidney was $13.9 \mathrm{~cm}$ in length \& $6.7 \mathrm{~cm}$ in breadth. The kidney was unrotated with the hilum facing anteriorly resulting in extra-renal vessels, calyces and pelvis. The hilum was $6.1 \mathrm{~cm}$ in length \& $3.3 \mathrm{~cm}$ in breadth. Its distance from the upper pole was $3.6 \mathrm{~cm} \&$ from the lower pole was $4.2 \mathrm{~cm}$. Neither artery nor the vein was crossing one another due to non rotation. Pelvis was the lowest structure to leave the hilum. Pelvis was extra-renal with the total length being $4.2 \mathrm{~cm}$. The length of the dilated part was $2.3 \mathrm{~cm} \&$ that of the tubular part was $1.9 \mathrm{~cm}$. Breadth of the most dilated part was $1.6 \mathrm{~cm} .5$ major calyces were observed, which were extra-renal in position. Left kidney was supplied by 2 arteries arising from the abdominal aorta. Normally the renal arteries arise from the lateral aspects of the aorta only a little below the origin of superior mesenteric artery, approximately at the level of upper part of $2^{\text {nd }}$ lumbar vertebra. (Hollinshed), hence upper artery was considered proper renal artery. The left proper renal artery arose from the lateral wall of 
abdominal aorta at the level of the first lumbar vertebra. Its length was $3.6 \mathrm{~cm}$. It divided into 2 branches, one entering the upper end of hilum \& $2^{\text {nd }}$ branch further dividing into two \& then entering the upper end of hilum. The additional renal artery originated from the abdominal aorta at the level of the third lumbar vertebra lateral to the inferior mesenteric artery. Its length was $4 \mathrm{~cm}$ to the point it divided into 3 branches. 2 branches entered the lower end of hilum \& uppermost branch traversed to the posteromedial border penetrating kidney directly, entering at a point $6.2 \mathrm{~cm}$ from upper end \& $5.1 \mathrm{~cm}$ from the lower end. Distance between the renal artery proper \& accessory renal artery was $3.9 \mathrm{~cm}$ at the hilum. 4 tributaries left the hilum $\&$ formed a single renal vein draining into the inferior vena cava. (FIGURE-1)

The size of the right kidney was $12.10 \mathrm{~cm}$ in length $\& 7.7 \mathrm{~cm}$ in breadth. It was also unrotated with the hilum facing anteriorly \& having extra-renal pelvis, vessels \& calyces. The length of the hilum was $5.7 \mathrm{~cm} \&$ breadth was $3.6 \mathrm{~cm}$. Distance of the hilum from upper pole was $3.7 \mathrm{~cm} \&$ from lower pole was $3.6 \mathrm{~cm}$. The length of the extra renal pelvis was $6.8 \mathrm{~cm}$. The length of the dilated part was $3.6 \mathrm{~cm} \&$ that of the tubular part was $3.2 \mathrm{~cm}$. Breadth of the widest part was $2 \mathrm{~cm} .5$ extra renal calyces were observed. Single artery entered the hilum, $3.7 \mathrm{~cm}$ from the upper pole \& $7.7 \mathrm{~cm}$ from the lower pole. The length of the artery was $7.8 \mathrm{~cm}$. It further divided into 2 branches. 3 tributaries at the hilum joined to form a single right renal vein, draining into the inferior vena cava. Calibre of the right renal artery was more as compared to the left. (FIGURE-2)

The abnormal rotation of the kidneys is often associated with ectopic kidneys; however in our case the kidney was located in the lumbar region between L1 and L3. No anomaly associated with the ureters was observed.

DISSCUSSION: There is nonconformity in the literature regarding the nomenclature of renal arteries other than the proper renal artery. They have been variously described as "accessory," "aberrant," "supernumerary," "supplementary," "multiple," "accessory aortic hilar," "aortic superior polar," "aortic inferior polar" and "anomalous". (2). To facilitate accurate reporting of incidence of additional renal arteries. Satyapal et al (3) made the following definition: An additional renal artery, other than the main renal artery, is one which arises from the aorta and terminates in the kidney. So in our case we use the term "additional renal arteries" for the same purpose. Abnormal rotation of kidneys, as in our case, often is caused by or related to additional vessels. (2) The abnormalities in the renal arteries are mainly due to the various developmental positions of the kidney [4]. The persistence of one of the fetal arteries is common (30\% of individuals), which usually arises from the aorta to the lower pole of the kidney [5].

There are two different opinions concerning the definite position of the kidneys in anatomical literature. According to the first, the kidney ascends in the retroperitoneal space during embryonic development. The renal rudiment forms in the pelvic region, at the level of L2-L3 vertebrae, with the dorsal convex border and the ventral hilum touching the abdominal wall. To place itself in the definite position, the kidney ascends and rotates. Between the 6th and the 9th week, the kidney ascends to the lumbar region, along the dorsal aorta. The exact mechanism is unknown. The role of an inductive substance secreted by the developing kidney is invoked. The second opinion says that the kidney undergoes pseudo ascend caused by the fast development of the caudal extremity of the fetus $[4,6,7]$. The factors that may interfere with the renal development are teratogenic agents, genetic factors, chromosomal anomalies, disorders in the fusion mechanism of 
the ureteric bud and the metanephrogenic blastema, medicines ingested by the mother [8]. There are, however, many idiopathic cases $[9,10]$. The kidney discussed in our cases has normal shape and size. Its position suggests that the factor(s) that affected the renal ascension interfered towards the end of the process, when the kidney was close to its final position. These factors also affected the rotation process.

\section{REFERENCES:}

1. Gillaspie C., Miller L.I., and Baskin M.; Anomalous renal vessels and their surgical significance, Anat Rec., 11:77, 1916.

2. Alp Bayramoglu., Deniz Demiryurek, Kadriye M. Erbil,; Bilateral additional renal arteries and an additional right renal vein associated with unrotated kidneys, Saudi Med J 2003; Vol. $24(5)$

3. Satyapal KS, Haffejee AA, Singh B, Ramsaroop L, Robbs JV, Kalideen JM. Additional renal arteries incidence and morphometry. Surg Radiol Anat 2001; 23: 33-38.

4. K. L. Moore and T. V. N. Persaud, The Developing Human: Clinically Oriented Embryology, WB Saunders, Philadelphia, PA, USA, 7th edition, 2002.

5. V. Singh, Anatomy of Abdomen and Lower Limb, Elsevier, New York, NY, USA, 2011.

6. PATTEN BM, Human Embryology, McGraw-Hill Book Co., New York-Toronto-London, 1953.

7. GUIDONI P, Embryologie, Editions Doin Deren et Cie Paris, 1968.

8. GÜLSÜN M, BALKANCI F, ÇEKIRGE S, DEGER A, Pelvic kidney with an unusual blood supply: angiographic findings, Surg Radiol Anat, 2000, 22(1):59-61.

9. GÖDDE S, Die Beckenniere, Dtsch Med Wochenschr, 1968, 93(20):1013-1017.

10. HERTZ M, RUBINSTEIN ZJ, SHAHIN N, MELZER M, Crossed renal ectopia: clinical and radiological findings in 22 cases, Clin Radiol, 1977, 28(3):339-344

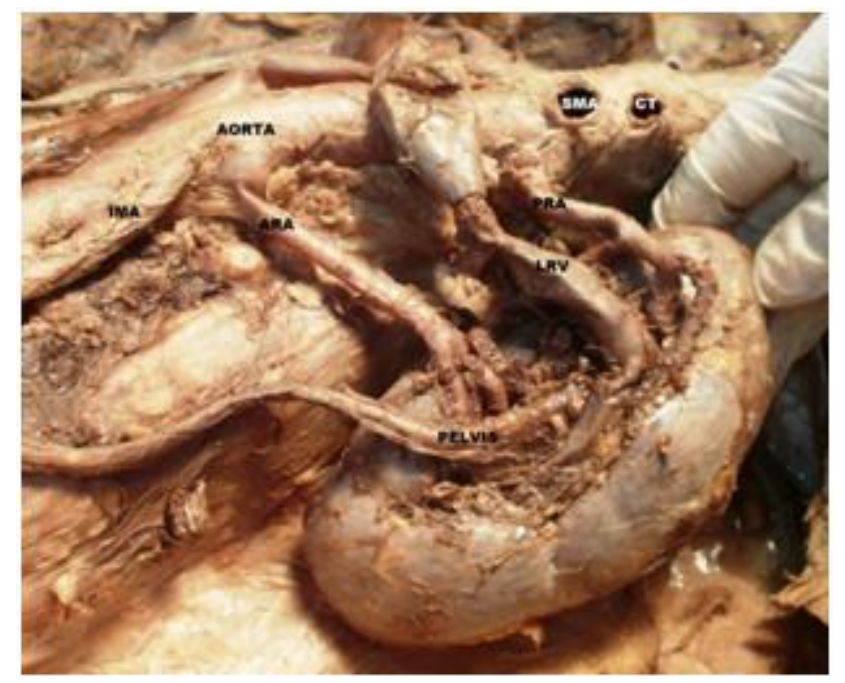

Fig 1: PRA-proper renal artery, ARA-Accessory renal artery, LRV- left renal vein, CT- celiac trunk, SMA- superior mesenteric artery, IMA- inferior mesenteric artery 


\section{CASE REPORT}

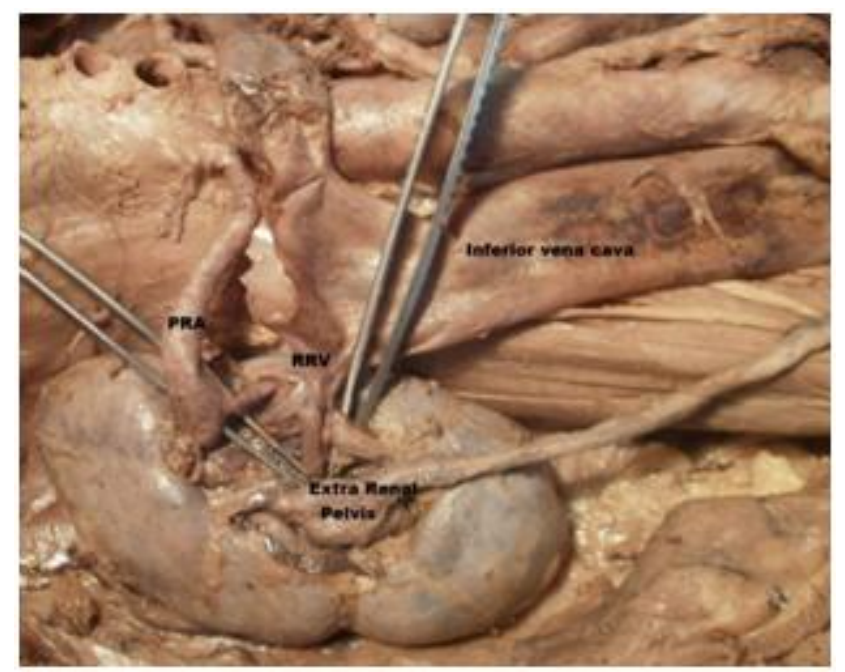

Fig 2: PRA-proper renal artery, RRV- right renal vein

\section{AUTHORS:}

1. Sheenu Malik Suri

2. Vandana Jain

3. S. Shrivastava

4. Arvind Jain

\section{PARTICULARS OF CONTRIBUTORS:}

1. Assistant Professor, Department of Anatomy, Mahatma Gandhi Memorial Medical College, Indore.

2. Assistant Professor, Department of Anatomy, Mahatma Gandhi Memorial Medical College, Indore.

3. Professor and Head of Department, Department of Anatomy, Mahatma Gandhi Memorial Medical College, Indore.
4. Assistant Professor, Department of Conservative Dentistry \& Endodontics, Govt Dental College, Indore

\section{NAME ADDRESS EMAIL ID OF THE \\ CORRESPONDING AUTHOR:}

Dr. Sheenu Malik Suri,

24-D, Nanak Nagar,

Behind Indrapuri Colony, Indore.

Email - contact.suri@gmail.com

Date of Submission: 19/08/2013.

Date of Peer Review: 20/08/2013.

Date of Acceptance: 28/08/2013.

Date of Publishing: 03/09/2013 